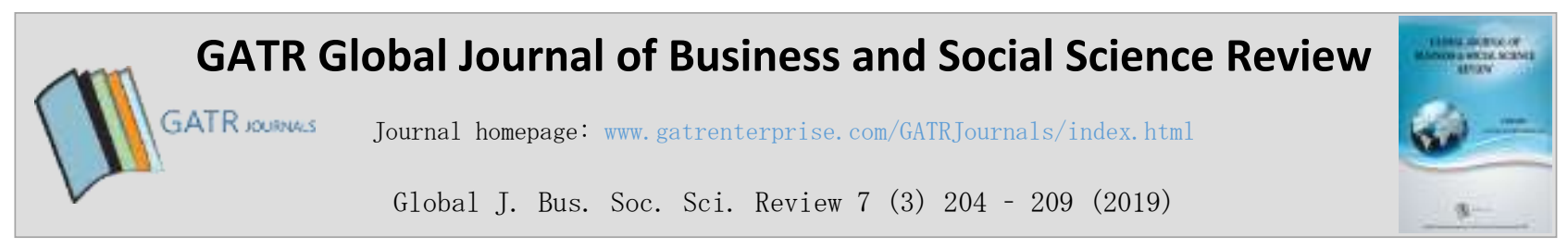

\title{
Assessing the Adoption of Learning Management Systems in Higher Education
}

\author{
WJAJM Lasanthika ${ }^{1^{*}}$, WDNSM Tennakoon $^{2}$ \\ ${ }^{1}$ Faculty of Graduate Studies, University of Kelaniya, 11600, Kelaniya, Sri Lanka \\ ${ }^{2}$ Department of Business Management, Wayamba University of Sri Lanka, 60200, Kuliyapitiya, Sri Lanka
}

\begin{abstract}
Objective - At present, higher educational institutions are heavily reliant on Learning Management Systems (LMS) to effectively manage communication with students and to enable technology-based learning. However, the success of LMS depends mostly on the adoption of LMS by students and teachers. The aim of this study is to incorporate different important factors of the Technology Acceptance Model to compare the behavioural intention of students and teachers to adopt LMS.

Methodology/Technique - Structured instruments are used for a sample of academics and undergraduates as the main contributors of LMS. The attitude towards LMS adoption of academics and students was compared.

Finding - The results suggest that the attitudes of teachers and students towards LMS adoption significantly differ as both contributors and users of LMS.

Novelty - In addition, the research highlights different aspects of LMS that can be manipulated for the successful adoption of LMS
\end{abstract}

Type of Paper: Empirical.

Keywords: LMS Adoption; Technology Acceptance Model (TAM); University Community; Attitude

Reference to this paper should be made as follows: Lasanthika, W.J.A.J.M; Tennakoon, W.D.N.S.M. (2019). Assessing the Adoption of Learning Management Systems in Higher Education, Global J. Bus. Soc. Sci. Review 7(3): 204 - 209. https://doi.org/10.35609/gjbssr.2019.7.3(5)

JEL Classification: A20, A23, A29.

\section{Introduction}

LMS is the prominent ICT platform over which blended learning is delivered. For higher education institutions, LMS is seen as a promising tool where the perpetual physical interaction of teacher and student is not guaranteed (Ashammari, 2015; Murshitha \& Wickramarachchi, 2016).

\footnotetext{
* Paper Info: Revised: July 11, 2019

Accepted: September 20, 2019

* Corresponding author: WJAJM Lasanthika

E-mail: jananijayawardana@gmail.com

Affiliation: Faculty of Graduate Studies, University of Kelaniya, 11600, Kelaniya, Sri Lanka
} 
Effective use of LMS enriches the learning experience for all stakeholders involved. The perspectives of both students and teachers of LMS adoption have been widely discussed in previous literature. However, a comparison of these two perspectives has not yet been provided.

Teachers and students are the dominant players in the learning experience. Communal involvement of both parties governs the productivity of learning experiences. As such, an effective use of LMS as a learning tool will depend on the active involvement of both teachers and students. Whilst academics are regarded as the significant influencers in promoting and enhancing the use of LMS (Alshammari, 2015), students also hold an equal share of responsibility to generate greater LMS adoption. The adoption of LMS by teachers is believed to be influenced by perceived ease of use, perceived usefulness, attitude toward usage and job relevance (Alharbi \& Drew, 2014). Meanwhile, for students, factors such as attitude towards LMS, selfefficiency, experience and interaction with lecturers and other classmates are of significant influence (Murshitha \& Wickramarachchi, 2016).

These findings are grounded in different contexts where a comparison would affect the interplay of operational discrepancies of LMS. Thus, a comparative study of the perspectives of both teachers and students on LMS adoption in a solitary context is needed to understand the potential perceptual discrepancies that impede effective adoption of LMS. Hence, this study, in a unitary learning context, aims to investigate the potential differences and/or similarities of the perspectives of both teachers and students toward LMS adoption.

This paper is organized as follows. A survey of related literature and the development of the research model are provided in Section 2. Section 3 describes the sample, research variables, the ANOVA and multiple regression models employed in this paper. The results are reported in Section 4, Section 5 provides a discussion of the results and Section 6 concludes the paper.

\section{Literature Review}

Through the use of technology, teaching and learning can be made interactive and in turn the instructions become more effective (Ashrafzadeh \& Sayadian, 2015). Learning Management Systems (LMS) are one such technology that supports e-learning programs (Coskuncay, 2013). In higher education, LMS integration into teaching and learning has significantly increased (Ashrafzadeh \& Sayadian, 2015). LMS facilitates the learning process and the instructors involved, by developing and organizing the learning material and other relevant content.

Throughout the process of LMS, the involved personnel are able to manage the interacting activities between the learners and teachers, along with the individual needs of managing the students (tracking their performance and other relevant areas). LMS offers significant improvement measures for the enhancement of learning by students (Hussain et. al., 2011). The adoption of LMS in the learning sector are based on the objectives of enhancing the performance outcomes of the students as well as the teachers; thus, reflecting the cost-effective management of educational resources in general (Alahmari, 2016). Al-Adwan et. al (2013) document the effectiveness of electronic learning in terms of mitigating potential issues in educational organizations. LMS is an attractive approach to address these issues, due to its relatively inexpensive nature and the ease of adoption.

The role of instructors, students and educational institutions in the adoption of such technology is important (Mokhtar, 2018). Within the important factors of LMS (i.e. appropriate technology execution, evaluation of the effectiveness of LMS, the role of students and teachers), instructors play a vital role in the success of the adoption of e-learning processes (Goh, 2013). The teachers should be competent enough to use technology and their knowledge, experience and perception about the technology affect the integration of the technology in the e-learning process (Bhuasiri, 2012).

Within the pursuit of Student Centered Learning, most educational institutions have adopted more technology into their learning process to enable students to improve their own abilities and achieve higher

Global J. Bus. Soc. Sci. Review 7 (3) 204 -209 (2019) 
standards in contrast to the traditional learning styles (Silva, 2014). With the ever-present need to demonstrate value for money and maximise efficiency and effectiveness from training and development, often with restricted time and expense, the measurement of the impact of technology is of a constant interest and importance (Smedley, 2010). Despite the many advantages of e-learning systems, the transformation of education styles presents various challenges that significantly affect culture and the continuing need for the development of technological skills of students and staff (Al-Adwan \& Smedley, 2012). Saade et. al. (2007) points out that, in general, like any information system, user acceptance and usage are important measurements of system success. According to Al-Adwan et. al. (2013), students' involvement and acceptance must be considered, otherwise, advanced systems will most likely fail.

Many universities that offer e-learning services encounter various difficulties in terms of adopting successful strategies including the acceptance and effectiveness of delivering courses. More importantly, understanding students' acceptance of e-learning is considered as a major step toward implementing and developing a successful e-learning environment (Butorac, M., Nebic, Z \& Nemcanin, D., 2001). It is essential that developers and university management understand how students perceive and participate in an e-learning environment as well as how to apply an effective e-learning approach to improve the learning process (Kohang \& Durante, 2003). Moreover, exploring students' intentions and investigating the factors that impact students' beliefs about e-learning can help management to create new methods for attracting a larger number of students who are willing to be involved in e-learning systems (Park, 2009). Therefore, it is crucial to investigate issues that explain students' acceptance, intention and attitudes towards e-learning systems.

According to Fung and Yuen (2012), in the teaching and learning process, teachers and students are the two primary entities. They are closely related and interact with each other. Though teachers act as the primary implementers of technology integration, the success of blended learning relies heavily on the acceptance and involvement of both students and teachers. Previous literature on this topic presents several models that can be used to explain perceptions on the acceptance of, or behavioural intentions to use, new technology. One of the well-known models related to technology acceptance and use is the Technology Acceptance Model (TAM), originally proposed by Davis in 1986. The TAM has proved to be a theoretical model to explain and predict user behaviour of information technology (Legris, Ingham, \& Collerette, 2003).

Although the TAM was originally conceived as a model to explain technology adoption by users in business and commercial environments, it has been accepted as an appropriate research model in the educational context (Alharbi \& Drew, 2014). The TAM has been the most effective model for this purpose, with its remarkable element of "Perceived Usefulness (PU)", as it illustrates the potential needs of the enhanced performance of the technology to meet the needs of the users in a meaningful way. With respect to LMS deployment and the assessment of its acceptance among students and teachers, particularly in terms of their respective behavior towards LMS, significant outcomes are achieved through the use of the TAM (Jamil, 2017). In addition to this, the component of "Perceived Ease of Use-PEOU" also facilitates the interpretation of the behavioral intentions of the users towards a particular technology. It is favored by the recent increase in technological awareness by the younger generations;. Thus, positive impacts are anticipated on the attitudes of students towards the acceptance of LMS as an effective means of e-learning. By means of the two components of the TAM, the attitudes and the respective intentions of using the implemented technology are depicted in a collective manner (Alharbi, 2014).

It has been established from past studies that the implications of LMS as an effective e-learning platform have not been recognised across the developing nations (Jamil, 2017). In exploring the relevant literature, there a notable gap with respect to the analysis of LMS deployment or adoption. Hence, this study uses the TAM to better assist the research domain and the educational institutions.

\section{Research Methodology}

The authors designed a comparative study based on the TAM (Davis, 1986) where a quantitative inquiry was made using data collected through both online and manual surveys. Structured instruments were adopted

Global J. Bus. Soc. Sci. Review 7 (3) 204 -209 (2019) 
for academics (Alharbi \& Drew, 2014) and undergraduates (Cigdem \& Ozturk, 2016) which were validated by previous studies. The contributors to the attitude towards LMS adoption of academics and students were compared to unearth the divergences. The research instruments consist of two main sections. The first section incorporates items with nominal scales to identify the respondents' demographic information and the second section consists of items which measure their attitude towards LMS adoption, of which the responses are measured using a 5point Likert scale. The survey was distributed among academic staff and undergraduates. The participants of this study are academic members and undergraduates from a leading state university in Sri Lanka, namely, Wayamba University. To control the influence of other potential factors, academic members and students were limited to one faculty - Business Studies \& Finance - and the students were drawn from the 3rd level of study in the Business Management special degree programme. The distribution of 300 questionnaires resulted in 159 responses (Academic members - 24 and students - 135) by both means. In line with the study objective, correlation analysis, ANOVA and multiple regression analyses were performed to derive the results.

\section{Results \& Discussion}

The results of the ANOVA shows that the attitude towards LMS adoption of academic members significantly differs from that of students $(\mathrm{F}=51.58, \mathrm{df}=1, \mathrm{p}=0.000)$. Consequently, both parties also differ in their behavioural intention to use LMS $(\mathrm{F}=28.735$, $\mathrm{df}=1, \mathrm{p}=0.000)$. Self-efficacy, multimedia instruction, perceived satisfaction, interactivity in LMS, perceived usefulness and perceived ease of use were the significant contributors of students' attitude towards LMS adoption ( $\mathrm{r} 2=0.525,0.525,0.670,0.585$, 0.663 , and 0.551 respectively). For academics, the key factors were perceived ease of use, perceived usefulness and attitude towards usage ( $\mathrm{r} 2=0.760,0.777$ and 0.832 respectively).

The stepwise multiple regression analysis shows that perceived satisfaction, perceived usefulness and perceived ease of use can significantly predict the variability of students' attitude toward LMS adoption ( $\mathrm{r}=$ $.437 ; 43.7 \%$ ). Performance of the same analysis for academics revealed that all of the tested variables could collectively account for the total variance of the dependent variable $(\mathrm{r}=1.00 ; 100 \%)$. It is noteworthy that perceived ease of use and perceived usefulness are common influencers of attitude toward LMS adoption in both students and teachers. Additionally, attitude towards usage is also a significant predictor of teachers' attitude towards LMS adoption while students consider their satisfaction when adopting LMS.

\section{Conclusion}

LMS is a widely used blended learning tool, which is now adopted by almost all higher education institutions. The attitude towards the adoption of LMS by its key collaborators has not been the subject of significant empirical research. Hence, the aim of this study is to compare the attitudes towards LMS adoption by students and teachers. The quantitative research design reveals that these two parties significantly differ in their attitudes towards LMS adoption. Students perceive LMS based on their satisfaction, ease of use and usefulness whilst teachers' views on LMS are shaped by ease of use, usefulness and by their attitude towards LMS usage.

The study employs the TAM model to assess the attitudes and behavior of students and teachers towards the use of LMS as an educational platform. In this regard, the core constructs of the TAM have been used as the identified variables, including Perceived Ease of Use, Perceived Usefulness, Attitude Towards Use and Behavioral Intention. Accordingly, the study concludes that there is a significant variation between LMS adaptation of teachers and students which may hinder the advantages associated with it. The study also affirms the credibility of the TAM in facilitating the assessment of diverse technological deployments.

The findings of this study provide a greater understanding of how the attitudes of key players in the adoption of LMS are formed. An understanding of those factors affecting attitudes toward LMS will allow 
parties to implement LMS more successfully. Future research may wish to examine this issue in a different context to achieve broader results which are capable of being generalised.

\section{References}

Abbad, M. M., Morris, D., \& De Nahlik, C. (2009). Looking under the bonnet: Factors affecting student adoption of elearning systems in Jordan. The International Review of Research in Open and Distributed Learning, 10(2). https://doi.org/10.19173/irrodl.v10i2.596

Al-Adwan, A., \& Smedley, J. (2012). Implementing e-learning in the Jordanian higher education system: Factors affecting impact. International Journal of Education and Development using ICT, 8(1). https://www.learntechlib.org/p/188017/.

Al-Adwan, A., Al-Adwan, A., \& Smedley, J. (2013). Exploring students acceptance of e-learning using Technology Acceptance Model in Jordanian universities. International Journal of Education and Development using ICT, 9(2). https://www.learntechlib.org/p/130283/.

Alahmari, A., \& Kyei-Blankson, L. (2016). Adopting and implementing an e-learning system for teaching and learning in saudi public k-12 schools: the benefits, challenges, and concerns. World Journal of Educational Research, 3(1). https://www.researchgate.net/profile/Ayshah_Alahmari/publication/308301393_Adopting_and_Implementing_an_ELearning_System_for_Teaching_and_Learning_in_Saudi_Public_K-

12_Schools_The_Benefits_Challenges_and_Concerns/links/57dfe67e08ae0c5b6564b842.pdf

Alharbi, S., \& Drew, S. (2014). Using the technology acceptance model in understanding academics' behavioural intention to use learning management systems. International Journal of Advanced Computer Science and Applications, 5(1), 143-155. https://pdfs.semanticscholar.org/f996/9c881e6228723b0e6975abc190b30926d1ef.pdf

Alshetwi, Abdullah Saleh. "Quality of High-Tech E-learning in Saudi Universities." International Journal of u-and eService, Science and Technology 7, no. 6 (2014): 319-326.

Ashrafzadeh, A., \& Sayadian, S. (2015). University instructors' concerns and perceptions of technology integration. Computers in Human Behavior, 49, 62-73. https://doi.org/10.1016/j.chb.2015.01.071

Butorac, M., Nebic, Z \& Nemcanin, D. (2001). "Blended E-learning in Higher Education: Research on Students' Perspective". Issues in Information Science and information Technology, 8, pp.409-429

Cigdem, H., \& Ozturk, M. (2016). Factors affecting students' behavioral intention to use LMS at a Turkish postsecondary vocational school. The International Review of Research in Open and Distributed Learning, 17(3). https://doi.org/10.19173/irrodl.v17i3.2253

Coskuncay, F. (2013). A model for instructors' adoption of learning management systems: Empirical validation in higher education context. Turkish Online Journal of Educational Technology-TOJET, 12(2), 13-25. https://eric.ed.gov/?id=EJ1015409

Davis, F. D. (1985). A technology acceptance model for empirically testing new end-user information systems: Theory and results (Doctoral dissertation, Massachusetts Institute of Technology). https://dspace.mit.edu/handle/1721.1/15192

Fung, H., \& Yuen, A. (2012, August). Factors affecting students' and teachers' use of LMS-Towards a holistic framework. In International Conference on Hybrid Learning (pp. 306-316). Springer, Berlin, Heidelberg.

Goh, W. W., Hong, J. L., \& Gunawan, W. (2013, August). Exploring students' perceptions of learning management system: An empirical study based on TAM. In Proceedings of 2013 IEEE International Conference on Teaching, Assessment and Learning for Engineering (TALE) (pp. 367-372). IEEE. 10.1109/TALE.2013.6654463

Jamil, L. S. (2017). Assessing the behavioural intention of students towards learning management system, through technology acceptance model-case of Iraqi universities. Journal of Theoretical and Applied Information Technology, 95(16), 3825-3840. http://www.jatit.org/volumes/Vol95No16/11Vol95No16.pdf

Koohang, A., \& Durante, A. (2003). Learners' perceptions toward the web-based distance learning activities/assignments portion of an undergraduate hybrid instructional model. Journal of Information Technology Education: Research, 2, 105-113. https://www.learntechlib.org/p/111466/.

Murshitha, S. M., \& Wickramarachchi, A. P. (2013). A Study of Students' Perspectives on the Adoption of LMS at University of Kelaniya. http://ir.lib.seu.ac.lk/handle/123456789/1404

Park, S. Y. (2009). An analysis of the technology acceptance model in understanding university students' behavioral intention to use e-learning. Educational technology \& society, 12(3), 150-162. https://www.jstor.org/stable/pdf/jeductechsoci.12.3.150.pdf 
Saade, R., Nebebe, F., \& Tan, W. (2007). Viability of the" technology acceptance model" in multimedia learning environments: a comparative study. Interdisciplinary Journal of E-Learning and Learning Objects, 3(1), 175-184. https://www.learntechlib.org/p/44804/

Al-Adwan, A., Al-Adwan, A., \& Smedley, J. (2013). Exploring students acceptance of e-learning using Technology Acceptance Model in Jordanian universities. International Journal of Education and Development using ICT, 9(2). https://www.learntechlib.org/p/130283/ 